\title{
TITLE:
}

\section{Occupied Electronic States of $L i$ in Li, Li2O2, and Li2O Analyzed by Soft $X$-ray Emission Spectroscopy}

AUTHOR(S):

Mukai, Keisuke; Kasada, Ryuta; Sasaki, Kazuya; Konishi, Satoshi

\section{CITATION:}

Mukai, Keisuke ...[et al]. Occupied Electronic States of Li in Li, Li2O2, and Li2O Analyzed by Soft X-ray Emission Spectroscopy. The Journal of Physical Chemistry C 2020, 124(17): 9256-9260

\section{ISSUE DATE:}

2020-04-30

URL:

http://hdl.handle.net/2433/250786

\section{RIGHT:}

This document is the Accepted Manuscript version of a Published Work that appeared in final form in The Journal of Physical Chemistry C, copyright $\odot$ American Chemical Society after peer review and technical editing by the publisher To access the final edited and published work see https://doi.org/10.1021/acs.jpcc.0c02885; The full-text file will be made open to the public on 2 April 2021 in accordance with publisher's 'Terms and Conditions for Self-Archiving'.; This is not the published version. Please cite only the published version.; この論文は出版社版でありません。引用の際には 出版社版をご確認ご利用ください。 


\section{C: Energy Conversion and Storage; Energy and Charge Transport}

\section{Occupied Electronic States of $\mathrm{Li}$ in $\mathrm{Li}$, LiO, and LiO Analyzed by Soft X-ray Emission Spectroscopy \\ Keisuke Mukai, Ryuta Kasada, Kazuya Sasaki, and Satoshi Konishi}

J. Phys. Chem. C, Just Accepted Manuscript • DOI: 10.1021/acs.jpcc.0c02885 • Publication Date (Web): 02 Apr 2020

Downloaded from pubs.acs.org on April 4, 2020

\section{Just Accepted}

"Just Accepted" manuscripts have been peer-reviewed and accepted for publication. They are posted online prior to technical editing, formatting for publication and author proofing. The American Chemical Society provides "Just Accepted" as a service to the research community to expedite the dissemination of scientific material as soon as possible after acceptance. "Just Accepted" manuscripts appear in full in PDF format accompanied by an HTML abstract. "Just Accepted" manuscripts have been fully peer reviewed, but should not be considered the official version of record. They are citable by the Digital Object Identifier (DOI®). "Just Accepted" is an optional service offered to authors. Therefore, the "Just Accepted" Web site may not include all articles that will be published in the journal. After a manuscript is technically edited and formatted, it will be removed from the "Just Accepted" Web site and published as an ASAP article. Note that technical editing may introduce minor changes to the manuscript text and/or graphics which could affect content, and all legal disclaimers and ethical guidelines that apply to the journal pertain. ACS cannot be held responsible for errors or consequences arising from the use of information contained in these "Just Accepted" manuscripts. 


\title{
Occupied Electronic States of $\mathrm{Li}$ in $\mathrm{Li}, \mathrm{Li}_{2} \mathrm{O}_{2}$, and $\mathrm{Li}_{2} \mathrm{O}$ Analyzed by Soft X-ray Emission Spectroscopy
}

\author{
Keisuke Mukai $^{1 *}$, Ryuta Kasada ${ }^{2}$, Kazuya Sasaki $^{3}$, and Satoshi Konishi ${ }^{1}$ \\ ${ }^{1}$ Institute of Advanced Energy, Kyoto University, Gokasho, Uji, Kyoto 611-0011, Japan \\ 2 Institute for Material Research, Tohoku University, 2-1-1 Katahira, Aoba-ku, Sendai \\ 980-8577, Japan \\ ${ }^{3}$ Graduate School of Science and Engineering, Hirosaki University, Hirosaki, Aomori, \\ 036-8561, Japan \\ * Corresponding author: k-mukai@iae.kyoto-u.ac.jp
}

\begin{abstract}
Lithium metal and lithium oxides are components of lithium-oxygen $\left(\mathrm{Li}-\mathrm{O}_{2}\right)$ batteries. In order to accurately identify Li-compounds and understand the degradation mechanism, fundamental knowledge on electron structures of constituent elements is vital. However, experimentally-derived occupied states of Li has been missing due to their intrinsic difficulties in detection. Herein, using soft $\mathrm{X}$-ray emission spectroscopy, ultrahigh-energy-resolution spectra of $\mathrm{Li}-K$ were collected for three critical Li-compounds; $\mathrm{Li}, \mathrm{Li}_{2} \mathrm{O}_{2}$, and $\mathrm{Li}_{2} \mathrm{O}$. Large chemical shifts to lower energies and peak broadening were observed in compound specific $\mathrm{Li}-K$ and $\mathrm{O}-K$ spectra. Theoretical calculations confirm that these changes derive from the characteristic electronic configurations of $1 \mathrm{~s}$ and $2 p$ states with core level shifts in ${ }^{+} \mathrm{Li}$. The large chemical shift $(\sim 4.6 \mathrm{eV})$ between the $\mathrm{Li}$ and $\mathrm{Li}_{2} \mathrm{O}$ peaks was utilized to visualize the chemical state mapping of the $\mathrm{Li}$ metal/oxide phase, facilitating the identifications of chemical phases in Li compounds.
\end{abstract}

\section{Introduction}

$\mathrm{Li}-\mathrm{O}_{2}$ air battery has attracted significant attentions as alternative means of electrochemical storage because of their high specific energy densities. ${ }^{1}$ In $\mathrm{Li}-\mathrm{O}_{2}$ cells, $\mathrm{Li}$ metal anode is oxidized and release $\mathrm{Li}^{+}$ions into electrolyte on discharge; during charging, the process is reversed. Once conducted through the electrolyte, $\mathrm{Li}^{+}$reacts with $\mathrm{O}_{2}{ }^{2-}$ to form the final discharge product, lithium peroxides $\left(\mathrm{Li}_{2} \mathrm{O}_{2}\right)$, at cathode. The discharge product of lithium oxide $\mathrm{Li}_{2} \mathrm{O}$ is also possible which increases the specific energy stored, but reverse charging is hampered due to its insulating property. ${ }^{2,3}$ In addition 
to electrochemical storage, Li, Li-alloys, and lithium oxides can serve as an intense neutron source ${ }^{4,5}$ and a tritium breeder in fusion reactors. ${ }^{6,7} \mathrm{Li}$ metal and oxides are chemically reactive in ambient atmosphere to form impurity phases and corrosion products that can degrade performance and raise safety concerns. ${ }^{8,9}$ Chemical phase analysis of Li-containing products contributes to our understandings of chemical reactions in the system. Chemical state distribution of Li compounds were previously reported using electron energy loss spectroscopy and Auger electron microscopy. ${ }^{10,11}$ Analysis of Li compounds is often hindered by (i) low atomic number of Li (i.e. poor X-ray scattering power and extremely low photon energies at the $K$-edge), (ii) its high affinity to moisture resulting in compositional changes, ${ }^{12,13}$ and (iii) X-ray/electron irradiation-induced sample damage that occurs during characterizations. X-ray photoelectron spectroscopy (XPS) is a common technique to obtain quantitative insights of core electrons, including Li 1s electrons. ${ }^{3,6,14}$ But, even with high-resolution XPS, Li 1s peaks overlap as the shift of the binding energy is small compared to the energy resolution of XPS; a shift of less than $1.5 \mathrm{eV}$ is observed for the $\mathrm{Li} 1 \mathrm{~s}$ core levels between $\mathrm{Li}$ metal and $\mathrm{Li}_{2} \mathrm{O} .{ }^{14}$ Thus, additional peak decompositions by fitting are required. Léon et al. investigated the valence electron structures of $\mathrm{Li}_{2} \mathrm{O}$ and $\mathrm{Li}_{2} \mathrm{O}_{2}$ at the $\mathrm{O} K$-edge using soft X-ray emission spectroscopy (SXES) at a synchrotron facility; the resulting spectra describe the valence electron structure of $\mathrm{O} .{ }^{15}$ We note that $\mathrm{Li}$ valence electron structures must be determined experimentally for understanding nature of chemical bonds and identifying oxide phases with Li. High resolution $K$-edge spectral data can be 
exploited to visualize chemical state mapping on a microscopic scale, as demonstrated in our previous studies for $\mathrm{Be}(Z=4)$ and $\mathrm{B}(Z=5)$ compounds. ${ }^{16,17}$ Thus, in this study, the ultrahigh energy resolution $(\sim 0.2 \mathrm{eV})$ valence electron structures of $\mathrm{Li}$ in $\mathrm{Li}, \mathrm{Li}_{2} \mathrm{O}_{2}$, and $\mathrm{Li}_{2} \mathrm{O}$ were experimentally analyzed. We employ SXES with a high sensitive X-ray charge-coupled device attached to an electron probe microanalyzer (EPMA). ${ }^{18,19}$ SXES is a bulk-sensitive measurement that covers ultra-soft X-rays in the energy range of $50-170 \mathrm{eV}$ including $\mathrm{Li}-K$ emission at $54.1 \mathrm{eV}$ (i.e. $2 \mathrm{p} \rightarrow 1 \mathrm{~s}$ transition in Li). As the samples are metastable and may decompose during sample preparation or characterization, the obtained spectra are directly compared with density of states (DOS) calculated using density functional theory (DFT) with all-electron configurations for $\operatorname{Li}\left(1 \mathrm{~s}^{2} 2 \mathrm{~s}^{1}\right)$. Due to large errors in band calculations in oxides, ${ }^{20}$ not only a conventional functional based on the generalized gradient approximation (GGA) but also a hybrid functional are utilized in this study. Finally, we show chemical state mappings of $\mathrm{Li}$ and $\mathrm{Li}_{2} \mathrm{O}$ based on the knowledge of electron structures at the $K$-edge.

\section{Experimental and Computational Methods}

Lithium metal rods ( $>99.9 \%$, Mitsuwa Chemical Co., Ltd.), lithium peroxide ( $>99 \%$, Kojundo Chemical Laboratory Co., Ltd.) and lithium oxide powders ( $>99 \%$, Kojundo Chemical Laboratory Co., Ltd.) were analyzed. Li metal rod oxidation was carried out in air at $25^{\circ} \mathrm{C}$ for $10 \mathrm{~min}$, thereafter the sample was covered with oxidized layer. Part of the surface layer was physically peeled off and interface between metal and oxide phases was analyzed by an area measurement using SXES. X-ray

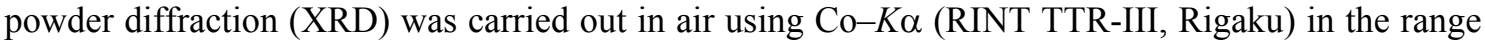


of $2 \theta=10-80^{\circ}$ at intervals of $0.02^{\circ}$ step. XRD data were analyzed using the RIETAN-FP program. ${ }^{21}$

The samples were analyzed by a JXA-8500F field emission EPMA by JEOL equipped with SXES (SS-94000SXES by JEOL). Sample powders were pressed on to carbon tape mounted on the sample holder. The measurement time and the acceleration voltages of the electron beam were $60 \mathrm{~s}$ and 2.0 $\mathrm{kV}$.

DFT calculations were performed using the Perdew-Burke-Ernzerhof (PBE) functional and HSE06 functional implemented in the Vienna ab initio simulation package (VASP). ${ }^{22-25}$ The electron configurations $1 \mathrm{~s}^{2} 2 \mathrm{~s}^{1}, 2 \mathrm{~s}^{2} 2 \mathrm{p}^{4}$ were used for the $\mathrm{Li}$ and $\mathrm{O}$ atoms, respectively. The $k$-point meshes of $6 \times 6 \times 6,8 \times 8 \times 4$, and $6 \times 6 \times 6$ were generated using the Monkhorst-Pack scheme for $2 \times 2 \times 2$ supercell of $\mathrm{Li}($ cubic; $\operatorname{Im} \overline{3} m), 2 \times 2 \times 1$ supercell of $\mathrm{Li}_{2} \mathrm{O}_{2}$ (hexagonal; $P 6_{3} m m c$ ), and $2 \times 2 \times 2$ supercell of $\mathrm{Li}_{2} \mathrm{O}($ cubic; $F m \overline{3} m$ ). A plane-wave cutoff energy of $400 \mathrm{eV}$ was used for calculations. Self-consistency was achieved with a tolerance for a total energy of $10^{-5} \mathrm{eV}$, and the atomic positions were relaxed until the force was less than $0.02 \mathrm{eV} \AA^{-1}$. The energy of DOS was referenced to the Li 1s band centroid, $E_{\mathrm{Li}-1 s}$. $E_{\mathrm{Li}-1 \mathrm{~s}}$ was calculated as follows;

$E_{\mathrm{Li}-1 s}=\frac{\int_{-\infty}^{E_{\max }} E g_{\mathrm{Li}-1 s}(E) d E}{\int_{-\infty}^{E_{\max }} g_{\mathrm{Li}-1 s}(E) d E}$

where $g_{\mathrm{Li}-1 \mathrm{~s}}(E)$ and $E_{\max }$ are the density of states of Li $1 \mathrm{~s}$ orbitals at $E$ and maximum energy of the $\mathrm{Li}$ 1s orbitals, respectively. 


\section{Results and Discussion}

$\mathrm{Li}_{2} \mathrm{O}_{2}$ and $\mathrm{Li}_{2} \mathrm{O}$ commercial powder samples were stored in an Ar-filled groove box and were

analyzed by XRD. Based on previous structural assessments on $\mathrm{Li}_{2} \mathrm{O}_{2},{ }^{26,27}$ Rietveld refinements were carried out using the structure proposed by Föppl et al. ${ }^{28}$ The results of multi-phase Rietveld analysis (Figure S1 in the Supporting Information (SI)) showed minor peaks for $\mathrm{LiOH}(P 4 / \mathrm{nmm})$ in addition to the $\mathrm{Li}_{2} \mathrm{O}_{2}\left(P 6_{3} m m c\right)$ and $\mathrm{Li}_{2} \mathrm{O}(F m \overline{3} m)$ phases. The $\mathrm{Li}_{2} \mathrm{O}_{2}$ and $\mathrm{Li}_{2} \mathrm{O}$ powders contained $\sim 6.3$ and $\sim 11.7$ w.t.\% LiOH as impurity phases, whereas no other impurity phase was found. Figure 1 shows Li DOS in $\mathrm{Li}, \mathrm{Li}_{2} \mathrm{O}_{2}$ and $\mathrm{Li}_{2} \mathrm{O}$ using the PBE exchange-correlation functional and Heyd-ScuseriaErnzerhof (HSE) hybrid functional. In Figure 1a, energetic difference in HSE between Li 1s centroid $\left(E_{\mathrm{Li}-1 \mathrm{~s}}\right)$ and $E_{\mathrm{F}}$ in Li metal was $50.1 \mathrm{eV}$ and had a significantly smaller error than that in PBE (46.4 $\mathrm{eV})$. The value was nevertheless underestimated compared to the experimental $(54.1 \mathrm{eV})$. PDOS calculations for $\mathrm{Li}_{2} \mathrm{O}_{2}$ (Figure 1b) indicated valence electron states of $\mathrm{Li}^{+}$ions composing of $\sigma_{\mathrm{g}}$ (bonding orbitals: $\mathrm{p}_{z}$ from -6.8 to $-3.5 \mathrm{eV}$ ), $\pi_{\mathrm{u}}$ (bonding orbitals: $\mathrm{p}_{x}$ and $\mathrm{p}_{y}$ from -6.8 to $-3.2 \mathrm{eV}$ ) and $\pi_{\mathrm{g}}{ }^{*}$ (antibonding: $\mathrm{p}_{x}$ and $\mathrm{p}_{y}$ from -2.5 to $0 \mathrm{eV}$ ), ${ }^{29}$ with a short gap approximately at $-3.2 \mathrm{eV}$ (Figure $1 \mathrm{~b}$ and Figure $\mathrm{S} 2$ in $\mathrm{SI})$. The $\mathrm{Li}_{2} \mathrm{O}$ band gap in $\mathrm{PBE}(4.9 \mathrm{eV})$ in Figure 1c was smaller than that in HSE $(5.9 \mathrm{eV})$ and the experimental value $(7.99 \mathrm{eV}) .{ }^{30}$ Energetic differences between $E_{\mathrm{Li}-1 \mathrm{~s}}$ and valence band maximum (VBM) in $\mathrm{Li}_{2} \mathrm{O}_{2}$ and $\mathrm{Li}_{2} \mathrm{O}$ were -46.6 and $-46.0 \mathrm{eV}$ in $\mathrm{HSE}$ (Figure 1 and Figure $\mathrm{S} 3$ in $\mathrm{SI}$ ). These indicate core level shifts as large as $3.5 \mathrm{eV}\left(\mathrm{Li}_{2} \mathrm{O}_{2}\right)$ and $4.1 \mathrm{eV}\left(\mathrm{Li}_{2} \mathrm{O}\right)$ for $\mathrm{Li}^{+}$. These shifts are at least an order of magnitude higher than the SXES energy resolutions, indicating their applicability 
for chemical state mapping. Core electron state in $\mathrm{Li}_{2} \mathrm{O}_{2}$ were at least two times wider than those in $\mathrm{Li}$ and $\mathrm{Li}_{2} \mathrm{O}$, due to difference of electron structures at two $\mathrm{Li}$ atom sites in $\mathrm{Li}_{2} \mathrm{O}_{2}$ (Figure $\mathrm{S} 3$ in $\mathrm{SI}$ ). This can be a cause of broad $\mathrm{Li}-K$ spectrum for $\mathrm{Li}_{2} \mathrm{O}_{2}$.
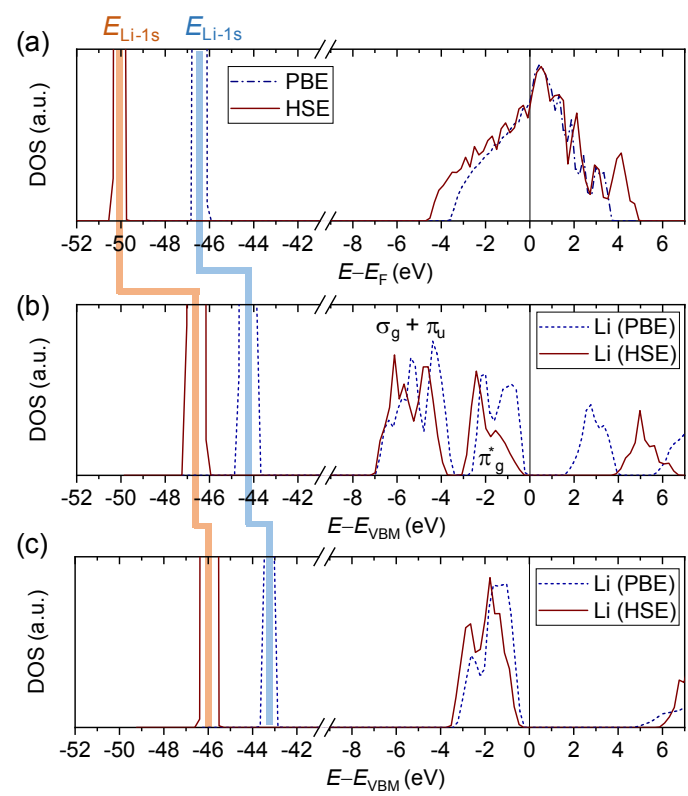

Figure 1 Electronic configurations of $\mathrm{Li}$ in $\mathrm{Li}(\mathrm{a}), \mathrm{Li}_{2} \mathrm{O}_{2}(\mathrm{~b})$, and $\mathrm{Li}_{2} \mathrm{O}$ (c) obtained by DFT using PBE and HSE. Orange and blue solid lines represent positions of Li $1 \mathrm{~s}$ centroid $\left(E_{\mathrm{Li}-1 \mathrm{~s}}\right)$ and indicate core level shifts of $\mathrm{Li}^{+}$.

Figure 2 shows the SXES spectra of the $\mathrm{Li}$ metal, $\mathrm{Li}_{2} \mathrm{O}_{2}$, and $\mathrm{Li}_{2} \mathrm{O}$ samples. In the obtained spectra, $n^{\text {th }}$-order peaks for $\operatorname{Li}(n=1)$ and $O(n=3-10)$ were observed; peaks of $C(n=2$ and 3$)$ were also observed due to the use of carbon conduction tape. The Li- $K$ spectrum of Li metal showed an asymmetric Doniach-Šunjić line shape in the range of $52-54.5 \mathrm{eV}$ (Fig. 2b). The Li-K peak intensities for $\mathrm{Li}_{2} \mathrm{O}_{2}$ and $\mathrm{Li}_{2} \mathrm{O}$ were significantly lower than that of $\mathrm{Li}$. Ionization to $\mathrm{Li}^{+}$causes numerous $\mathrm{Li}$ valence electrons to be lost, and results in poor signal to noise $(\mathrm{S} / \mathrm{N})$ ratios. In Figure 3, the SXES 
Li- $K$ spectra are directly compared with the DOS and PDOS of Li using HSE. The energy was referenced to $E_{\mathrm{Li}-1 \mathrm{~s}}$. The calculated $\mathrm{Li} 2 \mathrm{p}$ occupied states were convoluted with Gaussian functions with full width at half-maxima (FWHM) of $0.6 \mathrm{eV}\left(\mathrm{Li}\right.$ and $\left.\mathrm{Li}_{2} \mathrm{O}\right)$ and $0.9 \mathrm{eV}\left(\mathrm{Li}_{2} \mathrm{O}_{2}\right)$ because of the difference in 1s band width (Figure S3 in SI). The shapes of Li- $K$ spectra agreed well with the convoluted $2 \mathrm{p}$ state. The calculated energies using HSE were underestimated as large as $4.0 \mathrm{eV}$ for $\mathrm{Li}$ metal and $5.3 \mathrm{eV}$ for the oxides. A comparison between the experimental spectra and DOS using PBE (Figure S3 in SI) supports that the obtained spectral shapes describe Li valence electronic states. The $\mathrm{Li}-K$ spectrum for $\mathrm{Li}_{2} \mathrm{O}_{2}$ mainly derived from antibonding $\pi_{\mathrm{g}}{ }^{*}$ orbitals appeared at $49-52 \mathrm{eV}$, while the peak of bonding orbitals $\left(\sigma_{\mathrm{g}}\right.$ and $\left.\pi_{\mathrm{u}}\right)$ were below the SXES low-energy limit. But, the contributions of both bonding and antibonding orbitals were seen in the broad peak of $\mathrm{O}-K(4)$ for $\mathrm{Li}_{2} \mathrm{O}_{2}$ in Figure 2c. The $\mathrm{O}-K(4) \mathrm{FWHM}$ of the $\mathrm{Li}_{2} \mathrm{O}_{2}$ sample was 2.26 times wider than that from the $\mathrm{Li}_{2} \mathrm{O}$ sample (Figure 2c), which was consistent with the valence band width ratio of 2.12 calculated using HSE (Figure $1 \mathrm{~b}, \mathrm{c}$ ). The wide valence band was attributed to the anisotropic $2 \mathrm{p}$ states in $\mathrm{Li}_{2} \mathrm{O}_{2}$ (Figure $\mathrm{S} 2$ in $\mathrm{SI})$. Although the unidentified $\mathrm{O}-K$ peak in $\mathrm{Li}_{2} \mathrm{O}$ was observed at $528.9 \mathrm{eV}$ in the previous SXES results, ${ }^{15}$ no peak was found at the corresponding position of $132.2 \mathrm{eV}$ for $\mathrm{O}-K(4)$ in the $\mathrm{Li}_{2} \mathrm{O}$ spectrum in the present work. 
(a) $\mathrm{X}$-ray energy (eV)

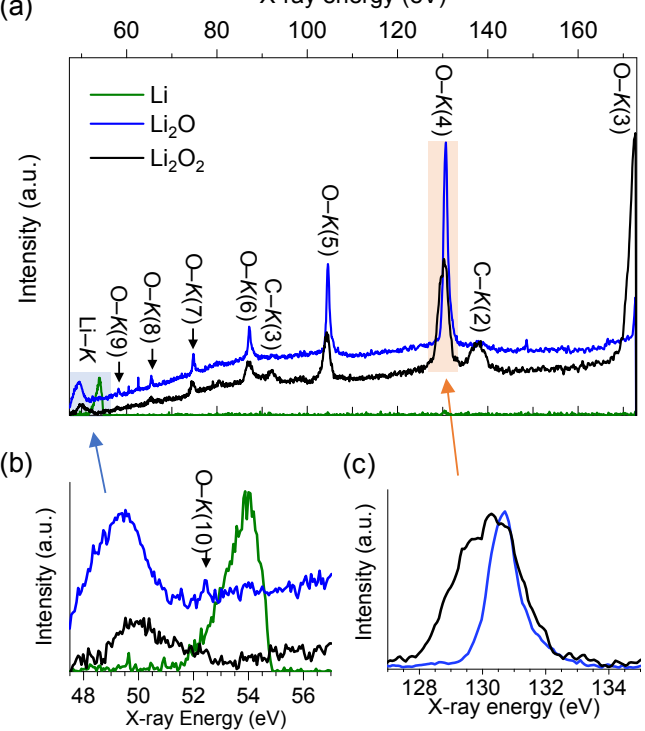

Fig. 2 SXES spectra from the $\mathrm{Li}$ metal, $\mathrm{Li}_{2} \mathrm{O}_{2}$, and $\mathrm{Li}_{2} \mathrm{O}$ samples in the energy ranges of $47.5-173 \mathrm{eV}$ (a), 47.5-57 eV for $\mathrm{Li}-K$ (b), and $127-135 \mathrm{eV}$ for $\mathrm{O}-K(4)$ (c), in which number in bracket denotes the $\mathrm{X}$-ray diffraction order. 
(a)

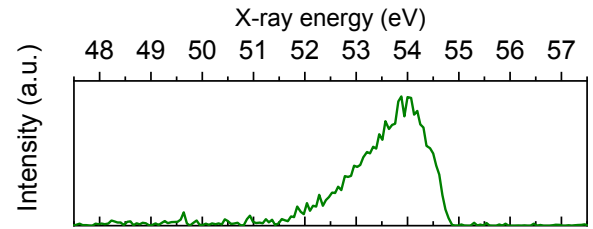

(b)

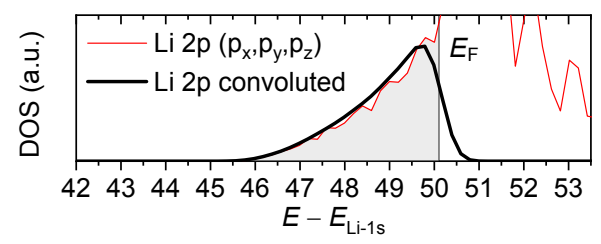

$\mathrm{X}$-ray energy (eV)

(c) $\quad \begin{array}{lllllllllll}48 & 49 & 50 & 51 & 52 & 53 & 54 & 55 & 56 & 57\end{array}$

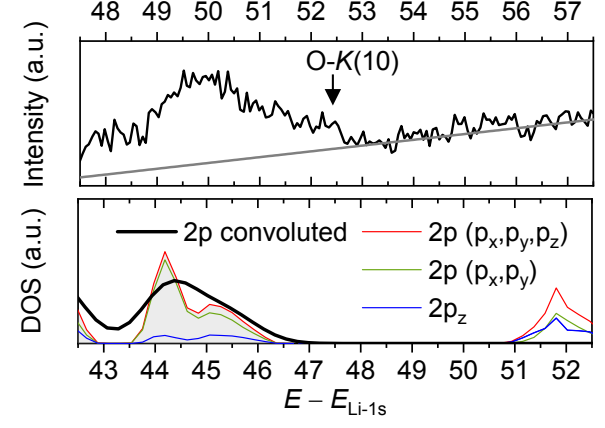

$\mathrm{X}$-ray energy (eV)

(e) $\quad \begin{array}{llllllllll}48 & 49 & 50 & 51 & 52 & 53 & 54 & 55 & 56 & 57\end{array}$

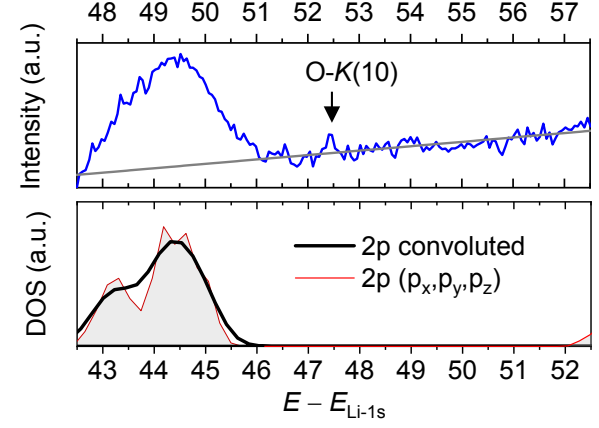

Figure 3 The experimental $\mathrm{Li}-K$ spectra for $\mathrm{Li}(\mathrm{a}), \mathrm{Li}_{2} \mathrm{O}_{2}(\mathrm{c})$, and $\mathrm{Li}_{2} \mathrm{O}(\mathrm{e})$ using the $\mathrm{SXES}$ compared to the convoluted DOSs of occupied $\mathrm{Li} 2 \mathrm{p}$ states in $\mathrm{Li}$ metal (b), $\mathrm{Li}_{2} \mathrm{O}_{2}\left(\mathrm{~d}\right.$ ), and $\mathrm{Li}_{2} \mathrm{O}$ (f) using HSE. Gray solid lines in panel (c) and (e) denotes linear background. Calculated energy is referenced to $\mathrm{Li}$ 1s centroid $\left(E_{\mathrm{Li}-1 \mathrm{~s}}\right)$ where occupied Li 2 p states below the Fermi energy and the VBMs are colored by gray. A comparison between the spectra and DOS using PBE is shown in Figure S3 in SI.

The chemical state and element mappings on a Li metal sample that has been naturally oxidized in air with a partial metallic surface are shown in Figure 4. The SXES spectra were collected at $40 \times$ 32 measuring points (1280 points), with an acquisition time of $30 \mathrm{~s}$ per pixel (pixel size: $1 \mu \mathrm{m} \times 1$ $\mu \mathrm{m})$. From the naturally oxidized Li metal sample, the $\mathrm{Li}-K$ spectra of $\mathrm{Li}_{2} \mathrm{O}(E<51 \mathrm{eV})$ and $\mathrm{Li}(>51$ 
eV) were observed without peak overlap. No $\mathrm{Li}_{2} \mathrm{O}_{2}$ peak was found from the collected data, as predicted by the MALT thermodynamic database (Table S1 in SI). Chemical state mappings were constructed by calculating integrated intensities in the following energy ranges: $\mathrm{Li}_{2} \mathrm{O}(47.5-51.0 \mathrm{eV})$ and Li metal (51.0-55.0 eV). Chemical state mappings (Figure 4a,b) visualize Li metal/oxide phase distribution on the sample; the metallic Li phase was distributed on the right side of the observed area, while the $\mathrm{Li}_{2} \mathrm{O}$ phase lies on the left. Together with $\mathrm{O}$ element mapping (Figure 4c), it is possible to distinguish the $\mathrm{Li}_{2} \mathrm{O}$ phase from other oxide phases with lacking $\mathrm{Li}$. To overcome $\mathrm{Li}-K$ weak emissions from oxide samples, an identification whether $\mathrm{Li}_{2} \mathrm{O}_{2}$ or $\mathrm{Li}_{2} \mathrm{O}$ phase can be accomplished by integrating their antibonding orbitals appeared in the range of 128-130 eV for $\mathrm{O}-K(4)$ (Figure $2 \mathrm{c}$ ).

(a)

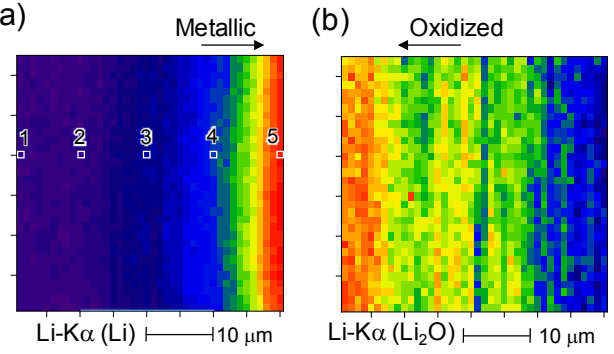

(c)

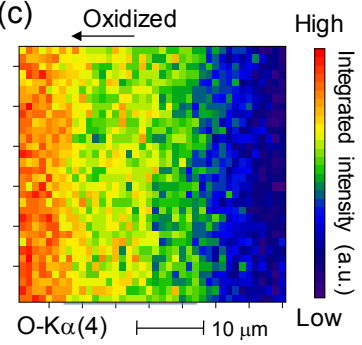

(d)

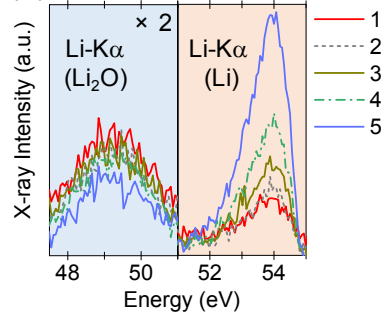

Fig.4 Chemical state mappings of Li metal $(E=51.0-55.0 \mathrm{eV})$ (a) and $\mathrm{Li}_{2} \mathrm{O}(E=47.5-51.0 \mathrm{eV})(\mathrm{b})$, element mapping of $\mathrm{O}$ using $4^{\text {th }}$ order $\mathrm{O}-K(E=129-132 \mathrm{eV})(\mathrm{c})$, and $\mathrm{Li}-K$ spectra at five measuring area (d). The positions of the five measuring area are shown in panel (a).

\section{Conclusion}

The electron structures in $\mathrm{Li}$ metal, $\mathrm{Li}_{2} \mathrm{O}_{2}$, and $\mathrm{Li}_{2} \mathrm{O}$ were experimentally analyzed using soft X-

ray emission spectroscopy. The chemical shifts of $\mathrm{Li}-K$ and peak broadening of $\mathrm{Li}_{2} \mathrm{O}_{2} \mathrm{O}-K$ arose from 
Li core level shifts and characteristic $2 p$ configurations as confirmed by theoretical calculations using the hybrid functional. A large chemical shift $(\sim 4.6 \mathrm{eV})$ without peak overlap was utilized to visualize the chemical state mappings of Li and lithium oxide. Insights of Li electron structures are a basis for investigating bond nature of $\mathrm{Li}$ and analyzing chemical state which could help further studies for controlling degradation processes.

\author{
ASSOCIATED CONTENT \\ Supporting Information \\ The supporting information is available free of charge on the ACS Publications website. \\ Rietveld patterns of the X-ray diffraction data, DOS of the Li and lithium oxides using HSE, core electron states using \\ HSE and crystal structure of $\mathrm{Li}_{2} \mathrm{O}_{2}$, comparison between the experimental spectra and DOS using PBE, phase change \\ of Li metal in air by thermodynamic calculations (Figures S1-S4 and Table S1). \\ SI.pdf
}

\author{
Author Information \\ Corresponding authors \\ Correspondence and requests for materials should be addressed to K. Mukai (k-mukai@iae.kyoto-u.ac.jp).
}

Notes

The authors declare no competing financial interest.

\title{
Acknowledgement
}

This work is supported by the Joint Usage/Research Program on Zero-Emission Energy Research, Institute of Advanced Energy, Kyoto University (ZE29A-12, ZE30A-09, ZE31A-24).

\section{Reference}

1. Bruce, P. G.; Freunberger, S.A.; Hardwick, L. J.; Tarascon, J. M.; Li- $\mathrm{O}_{2}$ and Li-S batteries with high energy storage. Nat. Mater. 2012, 11, 19-29. 
2. Zhang, S. S.; Foster, D.; Read, J. Discharge characteristic of a non-aqueous electrolyte $\mathrm{Li} / \mathrm{O}_{2}$ battery. $J$. Power Sources 2010, 195, 1235-1240.

3. Yao, K. P.; Kwabi, D. G.; Quinlan, R. A.; Mansour, A. N.; Grimaud, A.; Lee, Y. L.; Lu, Y. C.; ShaoHorn, Y. Thermal stability of $\mathrm{Li}_{2} \mathrm{O}_{2}$ and $\mathrm{Li}_{2} \mathrm{O}$ for Li-air batteries: In situ XRD and XPS studies. $J$. Electrochem. Soc. 2013, 160, A824-A831.

4. Horiike, H.; Murata, I.; Iida, T.; Yoshihashi, S.; Hoashi, E.; Kato, I.; Hashimoto, N.; Kuri, S.; Oshiro, S. Liquid Li based neutron source for BNCT and science application. Appl. Radiat. Isot. 2015, 106, 92-94.

5. Kamada, S.; Takada, M.; Suda, M.; Hamano, T.; Imaseki, H.; Hoshi, M.; Fujii, R.; Nakamura, M.; Sato, H.; Higashimata, A.; Arai, S. Development of target system for intense neutron source of $\mathrm{p}-\mathrm{Li}$ reaction. Appl. Radiat. Isot. 2014, 88, 195-197.

6. Tanaka, S.; Taniguchi, M.; Tanigawa, H. XPS and UPS studies on electronic structure of $\mathrm{Li}_{2} \mathrm{O} . J$. Nucl. Mater. 2000, 283, 1405-1408.

7. Mertens, M. A.; Aerts, A.; Infante, I.; Neuhausen, J.; Cottenier, S. Po-Containing Molecules in Fusion and Fission Reactors. J. Phys. Chem. Lett. 2019, 10, 2879-2884.

8. Wu, S.; Yi, J.; Zhu, K.; Bai, S.; Liu, Y.; Qiao, Y.; Ishida, M.; Zhou, H. A Super-Hydrophobic Quasi-Solid Electrolyte for $\mathrm{Li}_{2} \mathrm{O}_{2}$ Battery with Improved Safety and Cycle Life in Humid Atmosphere. Adv. Energy Mater. 2017, 7, 1601759.

9. Park, C.; Nozawa, T.; Kasada, R.; Tosti, S.; Konishi, S.; Tanigawa, H. The effect of wall flow velocity on compatibility of high-purity $\mathrm{SiC}$ materials with liquid $\mathrm{Pb}$-Li alloy by rotating disc testing for 3000 h up to $900{ }^{\circ} \mathrm{C}$. Fusion Eng. Des. 2018, 136, 623-627.

10. Wang, F.; Graetz, J.; Moreno, M. S.; Ma, C.; Wu, L.; Volkov, V.; Zhu, Y. Chemical distribution and bonding of lithium in intercalated graphite: Identification with optimized electron energy loss spectroscopy. ACS Nano 2011, 5, 1190-1197.

11. Ishida, N.; Fukumitsu, H.; Kimura, H.; Fujita, D. Direct mapping of Li distribution in electrochemically lithiated graphite anodes using scanning Auger electron microscopy. J. Power Sources 2014, 248, 1118-1122.

12. Zhang, T.; Zhou, H. A reversible long-life lithium-air battery in ambient air. Nat. comm. 2013, 4, 17.

13. Terai, T.; Mohri, H.; Takahashi, Y. Equilibrium pressure of water vapor over a $\mathrm{Li}_{2} \mathrm{O}(\mathrm{s})-\mathrm{LiOH}(\mathrm{s}, 1)$ mixture. J. Nucl. Mater. 1991, 179, 808-811.

14. Wood, K. N.; Teeter, G. XPS on Li-battery-related compounds: analysis of inorganic SEI phases and a methodology for charge correction. ACS Appl. Energy Mater. 2018, 1, 4493-4504.

15. Léon, A.; Fiedler, A.; Blum, M.; Benkert, A.; Meyer, F.; Yang, W.; Bär, M.; Scheiba, F.; Ehrenberg, H.; Weinhardt, L.; Heske, C. Valence Electronic Structure of $\mathrm{Li}_{2} \mathrm{O}_{2}, \mathrm{Li}_{2} \mathrm{O}, \mathrm{Li}_{2} \mathrm{CO}_{3}$, and $\mathrm{LiOH}$ Probed by Soft X-ray Emission Spectroscopy. J. Phys. Chem. C 2017, 121, 5460-5466. 
16. Kasada, R.; Ha, Y.; Higuchi, T.; Sakamoto, K. Chemical State Mapping of Degraded B ${ }_{4}$ C Control Rod Investigated with Soft X-ray Emission Spectrometer in Electron Probe Micro-analysis. Sci. Rep. 2016, 6,25700 .

17. Mukai, K.; Kasada, R.; Yabuuchi, K.; Konishi, S.; Kim, J. H.; Nakamichi, M. Valence Electron and Chemical State Analysis of $\mathrm{Be}_{12} \mathrm{M}(\mathrm{M}=\mathrm{Ti}, \mathrm{V})$ Beryllides by Soft X-ray Emission Spectroscopy. $A C S$ Appl. Energy Mater. 2019, 2, 2889-2895.

18. Terauchi, M.; Takahashi, H.; Handa, N.; Murano, T.; Koike, M.; Kawachi, T.; Imazono, T.; Koeda, M.; Nagano, T.; Sasai, H.; Oue, Y. Ultrasoft-X-ray emission spectroscopy using a newly designed wavelength-dispersive spectrometer attached to a transmission electron microscope. J. Electron Microsc. 2011, 61, 1-8.

19. Takahashi, H.; Murano, T.; Takakura, M.; Asahina, S.; Terauchi, M.; Koike, M.; Imazono, T.; Koeda, M.; Nagano, T. Development of soft X-ray emission spectrometer for EPMA/SEM and its application. IOP Conf. Ser. Mater. Sci. Eng. 2016, 109, 012017.

20. Wang, L.; Maxisch, T.; Ceder, G. Oxidation energies of transition metal oxides within the GGA+ U framework. Phys. Rev. B 2006, 73, 195107.

21. Izumi, F.; Momma, K. Three-dimensional visualization in powder diffraction. Solid State Phenom. 2007, 130, 15-20.

22. Perdew, J. P.; Burke, K.; Ernzerhof, M. Generalized gradient approximation made simple. Phys. Rev. Lett. 1996, 77, 3865-3868.

23. Blöchl, P. E. Projector augmented-wave method. Phys. Rev. B 1994, 50, 17953-17979.

24. Kresse, G.; Furthmüller, J. Efficient iterative schemes for ab initio total-energy calculations using a plane-wave basis set. Phys. Rev. B 1996, 54, 11169-11186.

25. Heyd, J.; Scuseria, G.E.; Ernzerhof, M. Hybrid functionals based on a screened Coulomb potential. $J$. Chem. Phys. 2003, 118, 8207-8215.

26. Cota, L. G.; De La Mora, P. On the structure of lithium peroxide, $\mathrm{Li}_{2} \mathrm{O}_{2}$. Acta Crystallogr. 2005, 61, 133-136.

27. Chan, M. K.; Shirley, E. L.; Karan, N. K.; Balasubramanian, M.; Ren, Y.; Greeley, J. P.; Fister, T. T. Structure of lithium peroxide. J. Phys. Chem. Lett. 2011, 2, 2483-2486.

28. Föppl, H. Die Kristallstrukturen der Alkaliperoxyde. Z. Anorg. Allg. Chem. 1957, 291, 12-50.

29. Garcia-Lastra, J. M.; Bass, J. D.; Thygesen, K. S. Communication: Strong excitonic and vibronic effects determine the optical properties of $\mathrm{Li}_{2} \mathrm{O}_{2}$. J. Chem. Phys. 2011, 135, 121101.

30. Ishii, Y.; Murakami, J.; Itoh, M. Optical Spectra of Excitons in Lithium Oxide. J. Phys. Soc. Jpn. 1999, 68, 2236. 


\section{TOC GRAPHICS}

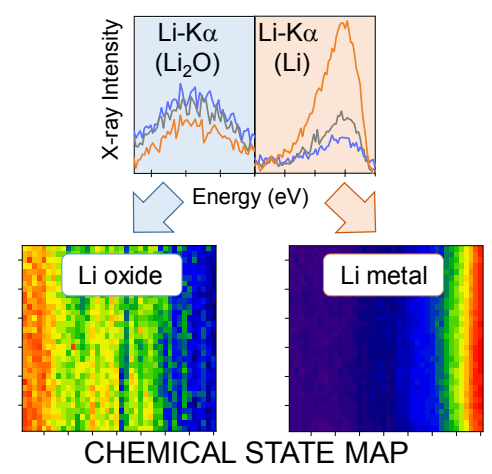

20

21 